\title{
PENGOPTIMALAN PERPUSTAKAAN SEKOLAH SMP BATIK PROGRAM KHUSUS SURAKARTA MELALUI APLIKASI SLIMS
}

\author{
Eko Purnomo \\ Pendidikan Bahasa dan Sastra Indonesia, Fakultas Keguruan dan Ilmu Pendidikan \\ Universitas Muhammadiyah Surakarta, \\ Email: a310170150@student.ums.ac.id \\ Zainal Arifin \\ Pendidikan Bahasa dan Sastra Indonesia, Fakultas Keguruan dan Ilmu Pendidikan \\ Universitas Muhammadiyah Surakarta, \\ Email: za135@ums.ac.id
}

Received : 05 July 2021

Revised : 19 September 2021

Accepted : 19 October 2021

DOI

\begin{abstract}
The school library is one of the crucial supporting facilities in learning. This study aims to describe the optimization of school libraries through the SLiMS application. This research is a qualitative research with the type of descriptive research. The data source in this study is the SLiMS application while the data is the use of the SLiMS application at the Surakarta Special Program Batik Junior High School for optimizing the school library. Data collection techniques are content analysis, observation and note-taking techniques. The data analysis method in this study uses an interactive model of Milles and Hubberman. The results of the study show that the optimization of the school library can be done by using the SLiMS application. This application can be used by librarians to manage school libraries. The optimizations are (1) arranging library administration for the Surakarta Special Program Batik Middle School, (2) classifying the books in the library, and (3) cataloging and attaching labels to books. With this optimization, it is hoped that it will support student achievement and higher interest in library.
\end{abstract}

Keywords: Libraries, SLiMS, Optimization

\section{PENDAHULUAN}

Perkembangan teknologi dan informasi tak dapat terbendungkan lagi. Perkembangan teknologi harus dapat dimaknai secara positif. Munculnya teknologi informasi tidak dapat dibendung dengan apapun, bahkan seiring berjalannya waktu teknologi informasi akan semakin berkembang (Harahap, 2021). Diperkuat pendapat Ganggi (2017) yang menyatakan bahwa perkembangan teknologi informasi yang pesat secara langsung berdampak pada perkembangan informasi, bersamaan dengan semakin mudahnya informasi dibuat, maka keterkinian informasi menjadi hal yang sulit untuk diikuti. Sekolah merupakan wadah bagi para siswa dalam membentuk kemampuan literasi informasi agar nantinya dapat bersaing di dunia global. Guna mengelola informasi yang cepat dan akurat tersebut maka perpustakaan, termasuk perpustakaan di perguruan tinggi, maka dikembangkan layanan perpustakaan berbasis teknologi informasi dan komunikasi (Pamungkas, 2018). 
Perpustakaan sekolah berperan sangat penting sebagai pusat sumber belajar dalam menyediakan dan melayankan informasi kepada pemustaka (Fiqri, dkk, 2021).

Kemudahan akses informasi di era sekarang memungkinkan seseorang lebih memilih internet dibanding perpustakaan untuk mendapatkan informasi. Perpustakaan sebagai lembaga penyedia informasi harus dapat memberikan pelayanan terbaik kepada pemustakanya apabila tidak ingin ditinggalkan (Rifauddin dan Habiburrahman, 2021). Perpustakaan sebagai sumber informasi harus mampu mengikuti perkembangan dan kemajuan zaman yang ada. Perpustakaan dapat berkembang dengan baik jika dapat mengikuti perkembangan yang ada. Perpustakaan adalah sebuah koleksi buku dan majalah. Walaupun dapat diartikan sebagai koleksi pribadi perseorangan, namun perpustakaan lebih umum dikenal sebagai sebuah koleksi besar yang dibiayai dan dioperasikan oleh sebuah kota atau institusi, dan dimanfaatkan oleh masyarakat yang rata-rata tidak mampu membeli sekian banyak buku atas biaya sendiri. Inilah yang disebut dengan perpustakaan konvensiona (Firman, dkk, 2016).

Dalam perpustaakan diperlukaan teknologi dan infromasi yang mendukung, karena fungsi perpustakan sebagai sumber belajar, memperoleh ilmu pengetahuan, dan menggunakan teknologi. Eskha (2018) menyatakan bahwa perpustakaan adalah suatu unit kerja dari suatu lembaga yang berisi koleksi buku sebagai penunjang dalam meningkatkan sumber belajar yang diatur untuk dibaca, dipelajari, dan dijadikan bahan rujukan. Menurut Puspitasari (2016) perpustakan sekolah harus mampu memberikaan pelayanan yang baik kepada anggota, petugas perpustakaan, dan pimpinan. Pelayanan yang baik dapat dilihat pada kemudahan anggota mendapatkan informasi yang cepat dan akurat. Jika pengolahan data perpustakaan masih dilakukan secara manual maka terdapat beberapa kendala yaitu lamanya mencari buku yang dicari, kesulitan petugas perpustakaan dalam mengelola data peminjaman, dan pengembalian karena harus selalu membuka catatan sehingga rentan terhadap kesalahan, kemudian semakin berjalannya waktu, petugas juga kesulitan memeriksa buku-buku yang semakin banyak dan yang sudah tidak perlu digunakan lagi.

Salah satu tugas perpustakaan adalah memberikan layanan informasi kepada pemustaka melalui layanan penelusuran. Penelusuran adalah kegiatan menelusur kembali seluruh atau sebagian informasi yang pernah ditulis atau diterbitkan melalui sarana temu kembali (Purwono dalam Puspa, 2015). Perpustakaan sekolah harus dikelola dengan baik agar dapat memberi pelayanan yang baik kepada anggota, petugas perpustakaan, dan 
pimpinan. Pelayanan yang baik dapat dilihat pada kemudahan anggota mendapatkan informasi yang cepat dan akurat. Jika pengolahan data perpustakaan masih dilakukan secara manual maka terdapat beberapa kendala yaitu lamanya mencari buku yang dicari, kesulitan petugas perpustakaan dalam mengelola data peminjaman dan pengembalian karena harus selalu membuka catatan sehingga rentan terhadap kesalahan, kemudian semakin berjalannya waktu, petugas juga kesulitan memeriksa buku-buku yang semakin banyak dan yang sudah tidak perlu digunakan lagi (Puspitasari, 2016). Perpustakaan SMP Batik PK merupakan salah satu sekolah swasta di Surakarta yang berdiri pada tahun 2014 dan sedang berkembang, oleh karena Perpustakaan sekolah tersebut belum sesuai standar Perpustakan menurut Undang-Undang. Penataan koleksi buku dalam Perpustakaan SMP Batik Program Khusus belum dilakukan secara maksimal dan masih banyak buku koleksi yang belum ditata sesuai dengan pedoman Perpustakaan Nasional. Salah satu komponen yang paling penting dalam sebuah perpustakaan adalah koleksi yang dimiliki oleh perpustakaan tersebut. Koleksi perpustakaan adalah semua bahan pustaka yang dikumpulkan, diolah, dan disimpan untuk disebarluaskan kepada masyarakat guna memenuhi kebutuhan informasi mereka (Yulia, dalam Wahyuni dan Rahmah, 2012).

Perpustakaan SMP Batik Program Khusus Surakarta memiliki WEB perpustaakaan yang sudah di sediakan dari Kemdikbud. WEB perpustakaan tersebut adalah SLiMS atau Senayan Library Management System. Senayan Library Management System (SLiMS) adalah perangkat lunak sistem manajemen perpustakaan (Library Management System) dari Pusat Informasi dan Humas Departemen Pendidikan Nasional Republik Indonesia ini dibangun dengan menggunakan PHP, basis data MySQL, dan pengontrol versi Git (Amaliah, 2016: Ridho, 2012:5). Perangkat lunak Senayan Library Management System (SLiMS) dibentuk para pengembang awal SLiMS tahun 2008. Anggota komunitas SLiMS ialah pustakawan yang berperan penting membuat inovasi dari interaksi dalam pertukaran pengetahuan dan menghasilkan karya yang beragam (Destrianto dan Heriyanto, 2020). Hal ini seperti dijelaskan oleh Azwar (2013) bahwa Senayan Library Management System atau biasa disingkat SLiMS merupakan salah satu Free Open Source Software (FOSS) berbasis web yang dapat digunakan untuk membangun sistem otomasi perpustakaan. Disimpulkan dalam penelitian (Arnomo, 2016) bahwa aplikasi SLiMS terdapat beberapa fitur pendukung.

Penelitian sebelumnya mengenai penggunaan aplikasi SLiMS di perpustakaan sudah pernah dilakukan peneliti sebelumnya, antara lain penelitian Cahyono dan Heriyanto (2014) menunjukkan bahwa aplikasi SLiMS memiliki banyak manfaat terutama dalam melakukan 
pengkatalogan buku. Menurut Iswanto, dkk (2016), bahwa penggunaan aplikasi SLiMS mampu memudahkan pekerjaan pustakawan. Penelitian relevan selanjutnya Costaner, dkk (2020) menyatakan bahwa SLiMS adalah perpustakaan aplikasi yang hampir sempurna untuk mengatur data dan informasi yang dibutuhkan. Selanjuatnya penelitian Iswanto, dkk (2019) bahwa pemanfaatan aplikasi SLiMS di perpustakaan Institut Agama Islam Negeri Curup dirasakan masih belum optimal karena Pustakawan yang ada masih terbatas mengerjakan tugastugas pokok mereka. Pustakawan hendaknya meningkatkan kemampuan mereka dalam memanfaat aplikasi SLiMS dengan menambah pengetahuan serta keterampilan mengenai aplikasi SLiMS serta meningkatkan skill pengoperasian perangkat komputer. Sehingga kinerja pada Perpustakaan Institut Agama Islam Negeri Curup dapat ditingkatkan.

SMP Batik Surakarta belum memiliki tenaga perpustakaan yang sesuai dengan kualifikasi keahlian dalam bidang perpustakaan. Hal ini dibuktikan bahwa di Perpustakaan SMP Batik Program khusus ketua perpustakaannya adalah guru IPS, sedangkan pustakawannya adalah Guru IPA. Hal ini masih belum sesuai dengan prosedur perpustakaan nasional. Melihat hal tersebut peneliti tertarik untuk melakukan pengoptimalan perpustakaan sekolah. Berdasarkan latar belakang di atas, maka perlu adanya pelatihan pengoperasian dan pengoptimalan penggunaan SLiMS bagi tenaga pustakawan di SMP Batik Program Khusus Surakarta.

\section{METODE}

Penelitian ini merupakan penelitian deskriptif kualitatif (Creswell, 2014; Zurqoni, dkk, 2019). Penelitian deskriptif kualitatif adalah jenis penelitian yang menggunakan data berupa kata-kata, tanpa ada rumus atau perhitungan (Mahsun, 2019). Lofland dan Lofland (dalam Moelong, 2010) sumber utama data yang digunakan dalam penelitian kualitatif yaitu frasa, kata, tindakan, ataupun kalimat, serta dapat berupa data tambahan misalnya dokumen atau yang lainnya. Sugiyono (2015) menyatakan bahwa penelitian kualitatif disebut juga dengan penelitian interprestasi yaitu penelitian yang menekankan interprestasi data yang ada di lapangan (Sumber data).

Penelitian ini dilaksanakan di Perpustakaan SMP Batik Program Khusus Surakarta. Perpustakaan SMP Batik Program Khusus yang berada di Jalan Slamet Riyadi No. 447, Pajang, Laweyan, Kota Surakarta. Waktu pelaksanaan penelitian yaitu kurang lebih satu bulan mulai tanggal 1 Maret - 25 Maret 2021. Sumber data dalam penelitian ini yaitu aplikasi SLiMS, adapun data dalam penelitian ini yaitu penggunaan aplikasi SLiMS di SMP Batik 
Program Khusus Surakarta untuk pengoptimalan perpustakaan sekolah. Teknik pengumpulan data dalam penelitian ini yaitu teknik observasi dan catat. Teknik observasi dilakukan peneliti untuk mengamati kegaitan di perpustakaan sekolah, di mana peneliti melakukan observasi di lapangan (SMP Batik PK Surakarta) selama satu bulan untuk mengumpulkan data yang digunakan dalam penelitian ini, sedangkan teknik catat dilakukan peneliti untuk mencatat permasalahan yang ada, setiap permasalahan yang ada dicatat untuk kemuadian diberikan solusi atas permasalahan tersebut. Analisis data dalam penelitian ini menggunakan model interaktif Milles dan Hubberman. Model interaktif Miles \& Huberman yang meliputi pengumpulan data, reduksi data, penyajian data, verfikasi, dan penarikan simpulan (Rijali, 2019).

\section{HASIL DAN PEMBAHASAN}

\section{Pengoptimalan Aplikasi SLiMS SMP Batik Program Khusus Surakarta}

Perpustakaan yang baik adalah perpustakaan yang mampu menerapkan dan mengimplementasikan penggunaan teknologi dan informasi. Dalam pembahasan penelitian ini akan dibahas bagaimana penggunaan sistem SLiMS sebagai salah satu teknologi yang dapat digunakan oleh perpustakaan dalam mengelola koleksi yang dimiliki oleh perpustakaan sekolah. Di bawah ini dijelaskan beberapa tahap dalam pengoptimalan perpustakaan Sekolah SMP Batik Program Khusus Surakarta dengan menggunakan aplikasi SLiMS yang sudah dimiliki oleh sekolah, tetapi belum pernah digunakan sama sekali dalam mengelola perpustakaan sekolah.

\section{Menyusun Administrasi Perpustakaan SMP Batik Program Khusus Surakarta.}

Katalog adalah daftar koleksi yang berada di perpustakaan dan disusun secara sistematis sehingga pengguna perpustakaan dapat mengetahui dengan mudah koleksi apa yang dimiliki oleh perpustakaan dan dimana koleksi tersebut dapat ditemukan. Katalog dijadikan alat sebagai rujukan yang paling penting di perpustakaan karena keterangan lengkap mengenai buku hanya terdapat di kartu katalog. Tujuan dari katalog perpustakaan adalah membantu pengguna untuk memperoleh informasi yang akan dibutuhkan.

Katalog yang ada di perpustakaan SMP Batik Program Khusus Surakarta memiliki 2 sistem, yaitu :

\section{a. Katalog Kartu}

Katalog kartu atau biasa disebut kartu catalog adalah bentuk catalog perpustakaan yang semua deskripsi bibliografinya dicatat pada kartu yang berukuran 7.5 x $12.5 \mathrm{~cm}$. Kartu 
katalog memuat keterangan singkat mengenai suatu buku meliputi : judul buku, nama pengarang, edisi, tempat terbit, nama penerbit, dan tahun terbit. Pengunaan kartu catalog memiliki kelebihan dan kelembahan. Kelebihan dari penggunaan katalog kartu adalah bersifat praktis, sehingga memudahkan dalam penambahan buku yang baru yang ada di perpustakaan. Sedangkan, kelemahannya adalah satu laci dalam katalog hanya memuat satu entri. Katalog kartu sudah tidak digunakan lagi dan beralih ke katalog online.

\section{b. Katalog Online}

Katalog online adalah catalog yang menyimpan data bibliografi dalam database computer. Dalam pembuatan catalog online dibutuhkan perangkat komputer dan apikasi tertentu sebagai penunjang kegiatan katalogisasi. Katalog online memiliki keunggulan dan kelemahan. Keunggulan katalog online adalah penelusuran informasi dapat dilakukan dengan cepat, tepat, penelusuran dapat dimana saja dan kapan saja. Sedangkan kelemahannya yaitu belum semua bahan pustaka masuk ke data computer sehingga penggunaan mengalami kesulitan dalam melakukan suatu penelusuran.

Katalog online yang digunakan oleh perpustkaan SMP Batik Program Khusus Surakarta menggunakan aplikasi tersendiri dari sekolah. Sistem catalog yang digunakan hampir sama dengan aplikasi Slims. Katalog online biasanya digunakan untuk menginput buku dan menceta label. Aplikasi SLiMS yang disedikan secara gratis oleh Kementerian Pendidikan dan Kebudayaan Republik Indonesia belum dapat digunakan oleh perpustakaan SMP Batik Program Khusus Surakarta. Salah satu hal yang terpenting dalam perpustakaan adalah administrasi perpustakaan.

SMP Batik Program Khusus Surakarta masih menggunakan administrasi model konvensional atau tradisional yaitu di mana semua administrasi dilakukan secara manual di dalam buku kerja perpustakaan. Administrasi manual tersebut antara lain yaitu daftar hadir peseta didik yang berkunjung ke perpustakaan, kartu peserta yang belum dimiliki siswa SMP Batik Program Khusus Surakarta, dan keanggotaan perpustakaan sekolah. Administrasi di SMP Batik Program Khusus Surakarta belum tertata secara prosedur perpustakaan yang sudah ditentukan. Hal ini dibuktikan bahwa dalam sistem SLiMS belum digunakan secara maksimal. Pada tahap awal peneliti pertama kali melakukan aktivasi sistem SLiMS. Setelah itu melakukan sistem keanggotaan. Keanggotaan dalam SMP Batik dibagi menjadi 2 yaitu peserta didik dan Guru/Tenaga pendidikan. Hal ini selaras dengan penelitian Ramadhan (2019) bahwa penerapan otomasi SLiMS (Senayan Library Management System) di Ruang Baca Pendidikan Administrasi Perkantoran Fakultas 
Keguruan dan Ilmu Pendidikan Universitas Sebelas Maret Surakarta meliputi: pelayanan sirkulasi, sistem temu kembali (OPAC), adminstrasi anggota, pengolahan bahan pustaka.

Masa keanggotaan untuk peserta didik di sesuaikan dengan tahun angkatan mereka. Untuk kelas 7 masa keanggotaan selama 3 tahun atau sampai lulus, sedangkan untuk kelas 8 masa keanggotaan selama 2 tahun, sedangkan untuk kelas 3 tidak diatur dalam aplikasi SLiMS, karena beberapa bulan ke depan akan lulus. Untuk masa keanggotaan guru dan tenaga pendidikan selama 5 tahun yaitu sampai 10 April 2026. Kartu anggota yang ada di Perpustakaan SMP Batik Program Khusus sudah dilengkapi dengan barkode sehingga memudahkan pustakawan dalam merekap kehadiran pemustaka yang hadir, karena sudah terekap dalam aplikasi SLiMS. Masa peminjaman buku diaplikasi SLiMS di SMP Batik Program Khusus selamama 2 minggu. Jika setlah 2 minggu peserta didik tidak mengembalikan buku tersebut, maka akan dikenakan denda 1.000/perharinya.

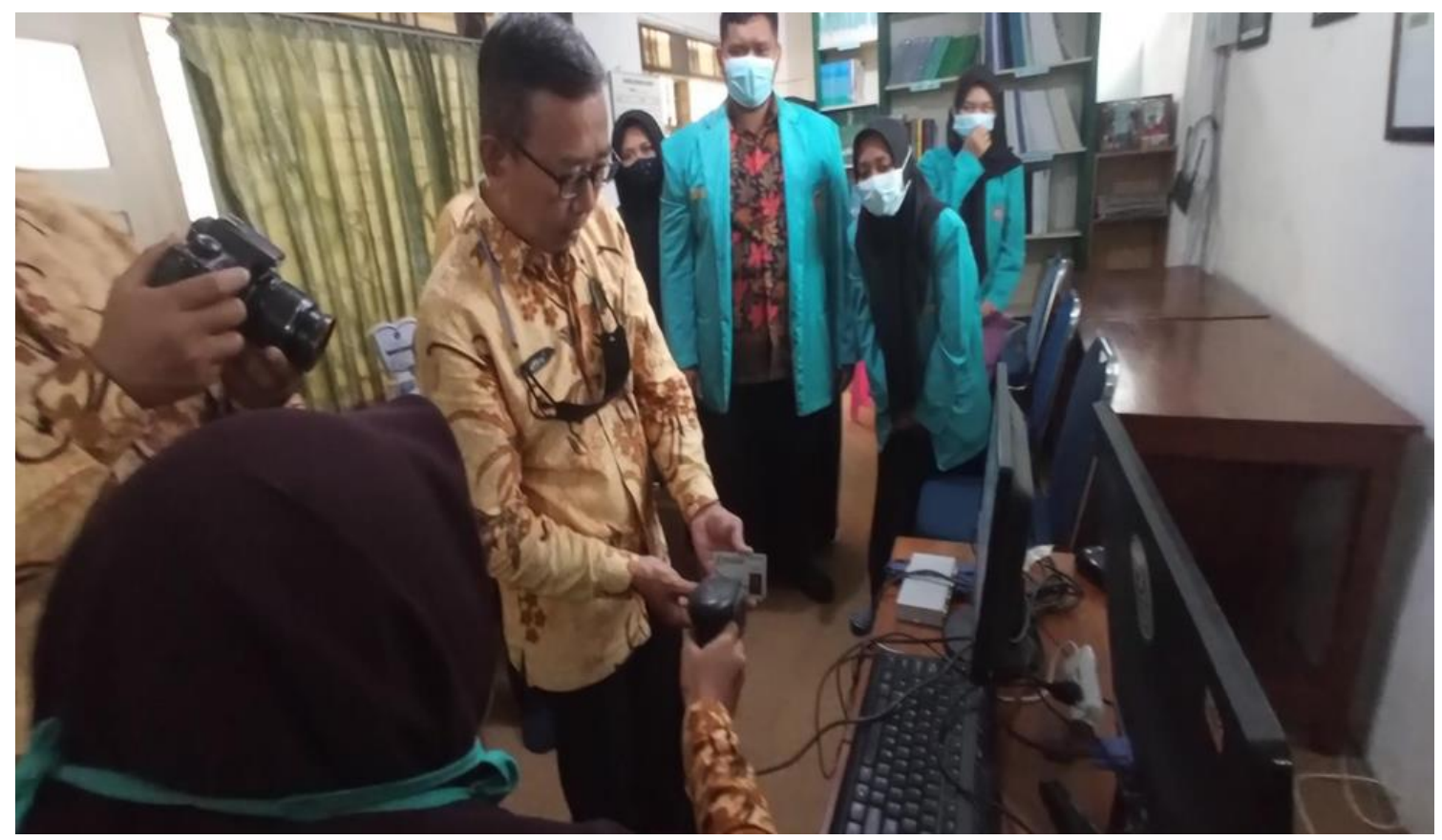

Gambar 1. Kepala Perpustakaan Mencoba Menggunakan Barkode dalam Aplikasi SLiMS

\section{Mengklasifikasikan Buku-Buku yang Ada di Perpustakaan}

SMP Batik Surakarta merupakan salah satu perpustakaan yang sedang berkembang, oleh karena itu perpustakaan Sekolah SMP Batik Program Khusus Surakarta belum memiliki banyak koleksi buku pendukung yang memadahi sesuai dengan ketentuan UUD Perpustakaan. Dalam perpustakaan ini hanya memiliki 3 rak buku.kebanyakan dari buku tersebut adalah buku pelajaran dan kumpulan soal, untuk buku dongeng, cerpen, novel 
sangat sedikit. Selain buku yang ada sedikit, belum ada penataan buku sesuai dengan klasifikasinya. Buku yang ditata hanya ada label buku saja, tanpa ada jenis buku tersebut. Untuk mengatasi hal tersebut peneliti melakukan perombakan koleksi buku yang ada. Buku yang tidak layak, karena rusak kami pisahkan dalam rak tersebut. Selain itu buku-buku kami klasifikasikan berdasarkan jenisnya. Klasifikasi buku tersebut antara lain buku pelajaran, kumpulan soal, kamus, novel (non fiksi), dan majalah. Buku-buku yang ada di Perpustakaan SMP Batik Program Khusus Surakarta semua belum diklasifikasi. Selain itu buku yang ada diinput dalam aplikasi SLiMS, sehingga memudahkan peserta didik mencari buku yang akan dipinjam. Perpustakaan dituntut dapat memberikan pelayanan yang baik, cepat dan tepat dengan menggunakan sarana OPAC berbasis SLiMS (Puspa, 2015)

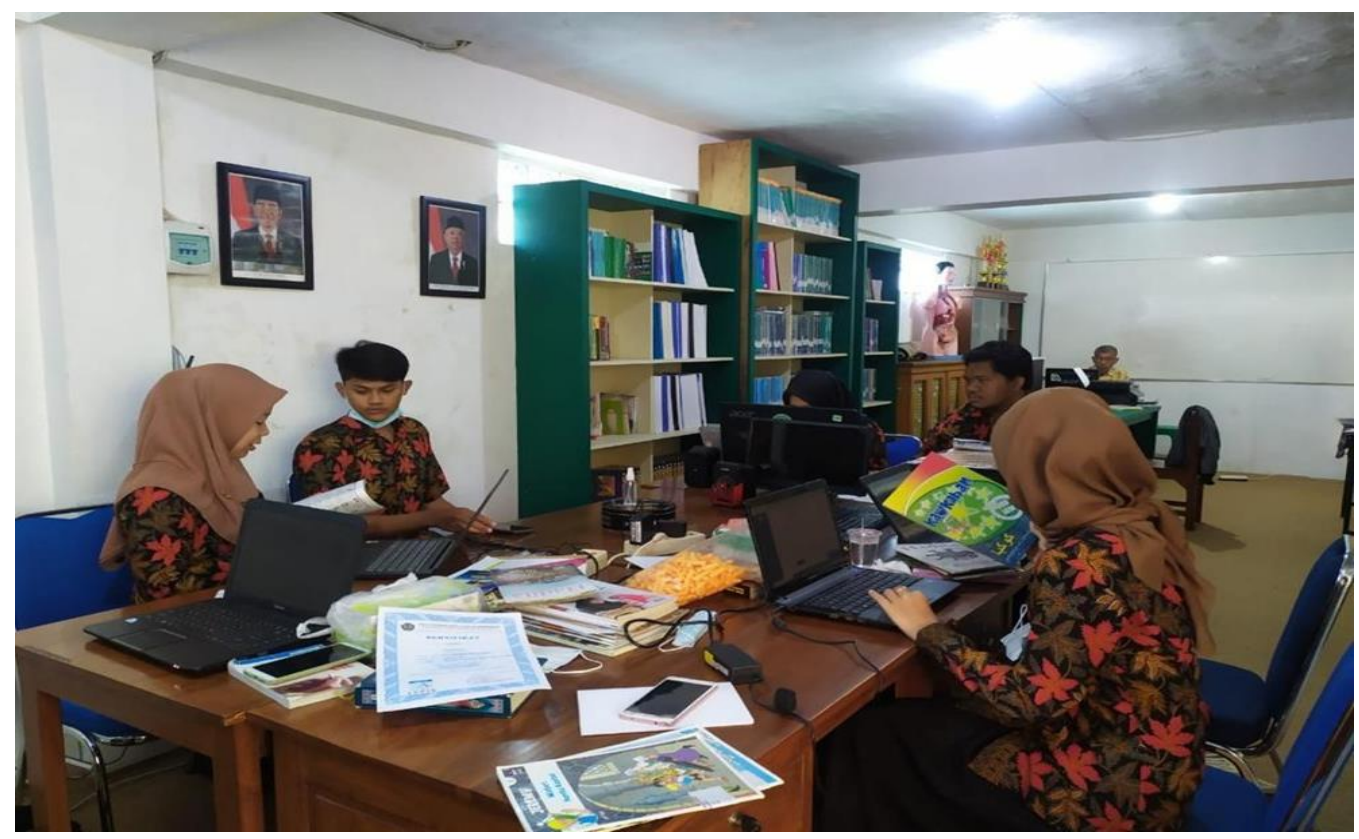

Gambar 2. Input Buku dalam Aplikasi SLiMS

\section{Melakukan Katalogisasi dan Penempelan Label pada Buku}

Selain mengklasifikasikan koleksi yang ada, kegiatan selanjutnya yang peneliti lakukan adalah memberikan pelabelan pada buku. Untuk melakukan pelabelan pada buku kami menggunakan aplikasi SLiMS. Dalam pengkatalogan dan pelabelan buku ada beberapa item yang harus diisi. Item tersebut antara lain :

1) Judul buku

2) Judul tambahan

3) Nama Pengarang
: Mengisiskan judul buku yang akan dikatalog.

: penjelasan yang ditulis langsung setelah judul utama

: Menuliskan nama pengarang dari buku 
4) Edisi

5) Impressium

6) Nomor seri

7) ISBN/ISSN

8) Deskripsi Fisik

9) Klasifikasi

10) No. Panggil berada
: Keterangan buku edisi ke berapakah

: Meliputi kota penerbit, penerbit, dan tahun terbit.

: Apabila memiliki nomor seri dari buku bisa dicantumkan.

: ISBN antara buku satu dengan buku yang lain berbeda, ISBN ada nomor buku dari pusat yang

memiliki nomor unik.

: Menjelaskan tentang berapa jumlah halaman buku dan ukuran buku.

: Klasifikasi buku berdasarkan DCC nya

: Menjelaskan no panggil buku, biasnaya

di cover bagian samping.

11) Ringkasan : Menceritakan tentang isi dari buku.

Setelah data tersebut masuk dalam bibliografi semua buku dapat terinput dalam SLiMS. Dapat dilakukan katalog buku, pelabelan buku, dan berapa jumlah buku yang ada secara otomatis. Hal ini memudahkan tugas pustakawan, karena tidak harus selalu melakukan pebelan buku secara manual. Dengan pemanfaatan aplikasi SLiMS ini diharapkan pustakawan mampu mempermudah pekerjaannya, selain itu meminimalisisr kesalahan dalam melakukan pendokumentasian buku koleksi yang ada. 


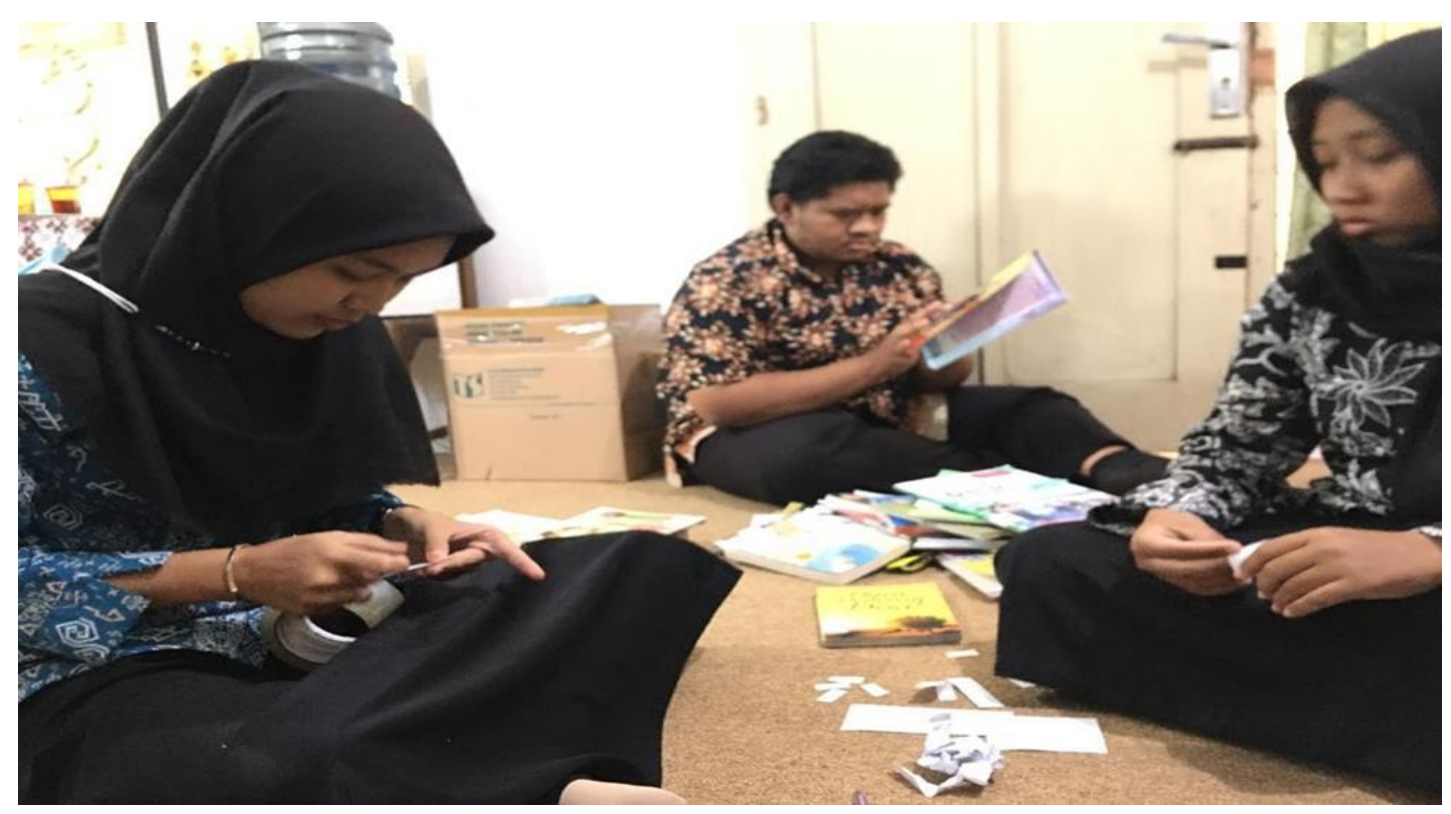

Gambar 3. Pelabelan Buku dari Aplikasi SLiMS

\section{Ucapan Terima Kasih}

Ucapan terima kasih yang mendalam kami ucapkan kepada SMP Batik Program Khusus Surakarta yang sudah membantu peneliti dalam melakukan penelitian ini. Petugas Perpustakaan SMP Batik Program yang dengan senang hati kami repotkan dalam pengambilan data penelitian.

\section{PENUTUP}

\section{Simpulan}

Dari hasil pembahasan yang telah diuraikan di atas dapat disimpulkan bahwa pengoptimalan perpustakaan sekolah dapat dilakakukan dengan menggunakan aplikasi SLiMS. Dengan mengoptimalkan perpustakaan SMP Batik Program Khusus Surakarta dapat mempermudah pekerjaan pustakawan dan peserta diidk. Salah satu cara mempermudah pekerjaan pemusataka yaitu tidak perlu menglakukan katalog secara manual atau konvensioanl. Adapun manfaat SLiMs bagi peserta didik yaitu dengan adanya aplikasi SLiMS mampu siswa mampu mengetahui koleksi apa saja yang tersedia dalam perpustakaan sekolah. Aplikasi ini dapat digunakan pustawakan untuk mempermudah pekerjaan dalam pengelolaan perpustakaan sekolah. Pengoptimalan yang dilakukan yaitu (1) Menyusun administrasi perpustakaan SMP Batik Program Khusus Surakarta, (2) Mengklasifikasikan buku-buku yang ada di perpustakaan, dan (3) Melakukan katalogisasi dan penempelan label pada buku. Dengan adanya pengoptimalan ini diharapkan dapat menunjang prestasi peserta didik serta minat untuk datang ke perpustakaan semakin tinggi. Penelitian ini hanya sebatas pengoptimalan dalam hal administrasi, pengkatalogan buku, dan 
pelabelan buku. Oleh karena itu diperlukan penelitian lanjutan untuk menyempurnakan penelitian ini.

\section{Saran}

Pengolahan perpustakaan SMP Batik Program Khusus juga sudah cukup baik. Akan tetapi, perpustakaan yang memenuhi kriteria standar haruslah terdapat pustakawan yang mengelola perpustakaan. Pustakawana tersebut dikhususkan hanya berada di perpustakaan dan mengolah bahan perpustakaan Untuk itu, perpustakaan SMP Batik Program Khusus akan lebih baik lagi jika perpustakaan dikelola setidaknya oleh 1 pustakawan yang berlatar belakang pendidikan perpustakaan. Selain itu perlu adanya pelatihan-pelatihan yang mendukung agar kerja pustakawan misalnya mengikuti workshop atau pelatihan yang berhubungan dengan pengelolaan perpustakaan sekolah.

\section{DAFTAR PUSTAKA}

Amaliah, R. (2016). Minat Mahasiswa Jurusan Ilmu Perpustakaan UIN Alauddin Makassar Terhadap Senayan Library Management System (SLiMS) dalam Pembelajaran Sistem Otomasi (Doctoral dissertation, Universitas Islam Negeri Alauddin Makassar). http://repositori.uin-alauddin.ac.id/1902/

Arnomo, I. (2016). Pemanfaatan Perangkat Lunak Open Source "SLiMS" untuk Repository Perguruan Tinggi. Studia Informatika: Jurnal Sistem Informasi, 9(2), 147-158. https://doi.org/10.15408/sijsi.v9i2.7644

Azwar, M. (2013). Membangun Sistem Otomasi Perpustakaan dengan Senayan Library Management System (SLiMS). Khizanah al-Hikmah: Jurnal Ilmu Perpustakaan, Informasi, dan Kearsipan, 1(1), 19-33. http://103.55.216.56/index.php/khizanah-alhikmah/article/view/23

Cahyono, J. E., \& Heriyanto, H. (2013). Analisis Pemanfaatan Senayan Library Management System (SLiMS) di Kantor Perpustakaan dan Arsip Daerah Kota Salatiga. Jurnal Ilmu Perpustakaan, 2(3), 139-152.

Costaner, L. (2020). Penerapan Sistem Sirkulasi Perpustakaan Berbasis SLiMS pada SMA IT Al Fityah Pekanbaru. Dinamisia: Jurnal Pengabdian Kepada Masyarakat, 4(2), 268-274. http://journal.unilak.ac.id/index.php/dinamisia/article/view/3926/2210

Creswell, J. W. (2014). Research Design: Qualitative, Quantitative, and Mixed Methods Approaches. America: United States of America. 
Destrianto, M. R., \& Heriyanto, H. (2020). Komunitas SLiMS Semarang sebagai ruang inovasi pustakawan. Jurnal Kajian Informasi \& Perpustakaan, 8(2), 119-132. https://journal.unpad.ac.id/jkip/article/view/23482/14512

Eskha, A. (2018). Peran Perpustakaan Sebagai Sumber Belajar. Jurnal Imam Bonjol: Kajian Ilmu Informasi dan Perpustakaan, 2(1), 12-18. https://journal.pustakauinib.ac.id/index.php/jib/article/view/25

Fiqri, A. M., Syahri, M., \& Ernaningsih, D. N. (2021). Tingkat Literasi Informasi Siswa MAN 1 Jembrana Menggunakan BIG 6 Model. JIPI (Jurnal Ilmu Perpustakaan dan Informasi), 6(1), 91-102. http://jurnal.uinsu.ac.id/index.php/jipi/article/view/9317/4314

Firman, A., Wowor, H. F., \& Najoan, X. (2016). Sistem Informasi Perpustakaan online berbasis Web. Jurnal Teknik Elektro dan Komputer, 5(2), 2936. https://doi.org/10.35793/jtek.5.2.2016.11657

Ganggi, R. I. P. (2017). Pendidikan Pemakai di Perpustakaan sebagai Upaya Pembentukan Pemustaka yang Literasi Informasi. Khizanah Al-Hikmah: Jurnal Ilmu Perpustakaan, Informasi, Dan Kearsipan, 5(1), 121-128. https://doi.org/10.24252/kah.v5i1a11

Harapahap, Wahfiuddin Rahmad. (2021). Penerapan Strategi Promosi Perpustakaan. JIPI: Jurnal Ilmu Perpustakaan \& Iinformasi, 6(1), 103-116. http://jurnal.uinsu.ac.id/index.php/jipi/article/view/9314/4317

Iswanto, R., Wince, I., \& Marleni, M. (2019). Optimalisasi Pemanfaatan Aplikasi SLiMS dalam Meningkatkan Kinerja Pustakawan pada Perpustakaan Institut Agama Islam Negeri Curup. Jurnal Ilmu Perpustakaan dan Informasi, 3(2), 159-192.

Iswanto, R., Wince, I., \& Marleni, M. (2019). Optimalisasi Pemanfaatan Aplikasi SLiMS dalam Meningkatkan Kinerja Pustakawan pada Perpustakaan InstitutAgama Islam Negeri Curup. Jurnal Ilmu Perpustakaan dan Informasi, 3(2), 159-190. http://journal.iaincurup.ac.id/index.php/TI/articl

Mahsun. (2019). Metode Penelitian Bahasa: Tahapan, Strategi, Metode, dan Tekniknya. Jakarta: Raja Grafindo Persada.

Moelong, Lexy. (2010). Metodologi Penelitian Pendidikan Edisi Revisi. Bandung: Remaja Rosdakarya.

Pamungkas, P. D. A. (2018). ISO 9126 Untuk Pengujian Kualitas Aplikasi Perpustakaan Senayan Library Management System (SLiMS). Jurnal RESTI (Rekayasa Sistem Dan Teknologi Informasi), 2(2), 465-471. https://doi.org/10.29207/resti.v2i2.398 
Puspa, E. (2017). Persepsi Pemustaka dalam Memanfaatkan Online Public Accces Catalog Berbasis Slims pada Perpustakaan Sekolah Tinggi Perikanan Jurusan Penyuluh Perikanan Bogor. Jurnal Pari, 1(1), 1-7.

Puspa, E. (2017). Persepsi Pemustaka dalam Memanfaatkan Online Public Accces Catalog Berbasis Slims pada Perpustakaan Sekolah Tinggi Perikanan Jurusan Penyuluh Perikanan Bogor. Jurnal Pari, 1(1), 1-7. $\quad$ http://ejournalbalitbang.kkp.go.id/index.php/JP/article/view/127/124

Puspitasari, D. (2016). Sistem Informasi Perpustakaan Sekolah berbasis Web. Jurnal Pilar Nusa Mandiri, 12(2), 227-240.

http://ejournal.nusamandiri.ac.id/index.php/pilar/article/view/277

Puspitasari, D. (2016). Sistem informasi perpustakaan sekolah berbasis web. Jurnal Pilar Nusa Mandiri, 12(2), 227-240. http://ejournal.nusamandiri.ac.id/index.php/pilar/article/view/277

Ridho, M. Rasyid. (2012). Senayan Library Management System For Dummies. Jakarta: SDC. https://iffatunnavisah.blogspot.com/2015/11/makalah-perpustakaanprofesipustakawan.html

Rifaudin, M., \& Habiburrahman. (2021). Studi Kasus Pengolahan Koleksi Jurnal Cetak di Perpustakaan Fakultas Psikologi Universitas Gadjah Mada Yogyakarta. JIPI (Jurnal Ilmu Perpustakaan dan Informasi), 6(1), 47-60. http://jurnal.uinsu.ac.id/index.php/jipi/article/view/7512/4310

Rijali, A. (2019). Analisis Data Kualitatif. Alhadharah: Jurnal Ilmu Dakwah, 17(33), 81-95. Sugiyono. (2015). Metode Penelitian Kuntitatif, Kualitatif, dan R\&D. Bandung. Alfabetas. Wahyuni, S., \& Rahmah, E. (2012). Pengembangan Koleksi Perpustakaan di Perpustakaan Kopertis Wilayah X. Ilmu Informasi Perpustakaan dan Kearsipan, 1(1), 351-357. https://doi.org/10.24036/1526-0934

Zurqoni, Z., Retnawati, H., Apino, E., \& Anazifa, R. D. (2019). Impact of Character Education Implementation: a Goal-Free Evaluation. Problems of Education in the 21st Century, 76(6), 881-899. https://doi.org/10.33225/pec/18.76.881 